\title{
Endocrine complications of topical and intralesional corticosteroid therapy
}

\author{
J A CURTIS, E CORMODE, B LASKI, J TOOLE, AND N HOWARD
}

Division of Endocrinology and Department of Paediatrics, University of Toronto, Ontario, and Department of Paediatrics, Soldier's Memorial Hospital, Orillia, Ontario, Canada

SUMMARY Four previously healthy children acquired skin problems that were treated with topical or intralesional fluorinated corticosteroids. Three developed signs that suggested Cushing's syndrome 1-4 months after initial treatment. Investigation showed low plasma cortisol levels and inadequate response to corticotrophin stimulation. After 7 months of treatment with topical steroids the fourth child presented with failure to thrive; during a febrile illness he had a convulsion followed by acute hypotension which responded to parenteral corticosteroid administration. Adrenal function was not studied in this patient. Although fluorinated corticosteroids seldom lead to overt adrenal suppression in children, they may impair pituitary-adrenal responses in some. Such patients should be given oral or parenteral steroid cover in the event of illness or trauma.

Complications associated with steroids have generally been associated with corticosteroids administered orally or intramuscularly to treat systemic disease since steroid is more often given by these routes than by others. The complications arising from topical or intralesional corticosteroid to treat skin disease are little known. Although it has been suggested that topical steroids are more hazardous in children than in adults, few reports have documented adverse clinical effects in children. Reported cases manifested failure to thrive, ${ }^{1-5}$ Cushing's syndrome ${ }^{4-8}$, wasting of the buttocks from local application, ${ }^{2}$ and benign intracranial hypertension. ${ }^{39}$ Despite suggestive clinical features in some of these, convincing biochemical evidence of disturbed steroid metabolism was seldom presented. Systemic complications of intralesional corticosteroid therapy are rare in adults ${ }^{10-12}$ and have not been reported in children.

The systemic effects of treatment with topical and intralesional steroids in 4 children are described. Suppression of the hypothalamic-pituitary-adrenal (HPA) axis was demonstrated in 3 , and a pronounced failure to thrive with acute adrenal insufficiency was shown in the fourth.

\section{Case reports}

Case 1. A 13-year-old girl presented with psoriasis of 4 months' duration. An erythematous papulosquamous rash, at first confined to the perianal region, had quickly become generalised and treatment with $0.5 \%$ hydrocortisone cream for 1 week brought no appreciable relief. After ultraviolet light treatment pustules developed and she became febrile and toxic. A diagnosis of von Zumbusch's pustular psoriasis was made and the patient was transferred to the Hospital for Sick Children in Toronto.

On admission her height was $147 \mathrm{~cm}$ (3rd centile) and weight $41.2 \mathrm{~kg}$ (10th centile). Initial management consisted of daily applications of dilute betamethasone-17-valerate cream. Lack of response necessitated a gradual increase in the strength of this preparation. During the next 9 weeks a total equivalent to $7900 \mathrm{~g}$ of $0.1 \%$ betamethasone cream (125 $\mathrm{g}$ daily) was applied. The psoriasis was reduced by this treatment but Cushingoid facies developed and striae appeared on the buttocks and thighs. The patient's blood pressure was $120 / 80 \mathrm{mmHg}$. Reduction of topical steroid was quickly followed by relapse of the skin condition and toxic state; it became necessary to introduce methotrexate therapy while stopping the cream under cover of oral steroids.

Investigation (Table) demonstrated suppression of the HPA axis. Normal diurnal variation of plasma cortisols returned 6 weeks after topical steroids had been stopped.

Case 2. A 14-month-old boy was brought to the emergency department of Orillia Soldier's Memorial Hospital with fever, vomiting, and anorexia of 12 
Table Plasma cortisol levels and responses to ACTH stimulation

\begin{tabular}{|c|c|c|c|c|c|c|}
\hline \multirow[t]{2}{*}{ Case } & \multirow[t]{2}{*}{ Time of investigation } & \multicolumn{2}{|c|}{$\begin{array}{l}\text { Plasma cortisol } \\
(\mu \mathrm{g} / 100 \mathrm{ml})\end{array}$} & \multicolumn{3}{|c|}{$\begin{array}{l}\text { B } 1-24 \text { ACTH response test } 19 \\
\text { Plasma cortisol }(\mu \mathrm{g} / 100 \mathrm{ml})\end{array}$} \\
\hline & & $\begin{array}{l}\text { O800 } \\
\text { hours }\end{array}$ & $\begin{array}{l}2000 \\
\text { hours }\end{array}$ & Baseline & +30 minutes & Increment \\
\hline 1 & $\begin{array}{l}\text { At presentation } \\
6 \text { weeks after stopping topical steroids }\end{array}$ & $\begin{array}{l}<1 \\
26 \cdot 3\end{array}$ & $<1$ & $<1$ & $\underline{-1}$ & $\mathbf{0}$ \\
\hline 3 & $\begin{array}{l}4 \text { weeks after final injection } \\
8 \text { weeks after final injection }\end{array}$ & $\begin{array}{r}4 \cdot 5 \\
10 \cdot 8\end{array}$ & $\stackrel{4}{-5}^{-5}$ & $10 \cdot 8$ & $\overline{12} \cdot 3$ & $1 \cdot 5$ \\
\hline 4 & $\begin{array}{l}7 \text { weeks after injection } \\
19 \text { weeks after injection }\end{array}$ & $\begin{array}{l}<1 \\
18 \cdot 5\end{array}$ & $\begin{array}{r}<1 \\
4 \cdot 5\end{array}$ & $\begin{array}{l}<1 \\
20 \cdot 1\end{array}$ & $\begin{array}{l}<1 \\
31 \cdot 0\end{array}$ & $\begin{array}{c}0 \\
10 \cdot 9\end{array}$ \\
\hline \multicolumn{2}{|c|}{ Normal values 19} & $7-22$ & $\begin{array}{l}<50 \% \\
\text { of } 0800\end{array}$ & value & $18-47$ & $7-25$ \\
\hline
\end{tabular}

Conversion: traditional to SI units: $1 \mu \mathrm{g} / 100 \mathrm{ml} \approx 27 \cdot 7 \mathrm{nmol} / 1$.

hours' duration, and was seen by one of us (EC). He had had a nappy rash since age 3 months and his mother had been applying $0.1 \%$ betamethasone- 17 valerate cream with each nappy change for the 7 months preceding admission.

On examination the child was drowsy and appeared dehydrated and malnourished. He was febrile and his blood pressure was $85 / 70 \mathrm{mmHg}$. Weight was $7.2 \mathrm{~kg}(<3 \mathrm{rd}$ centile). Stomatitis was noted. A large erythematous plaque with smaller satellite lesions were present over the buttocks and perineum. Laboratory studies gave the following results: leucocyte count $24 \times 10^{9} / 1$ (polymorphs $54 \%$, lymphocytes $25 \%$ ), serum sodium $121 \mathrm{mmol} / \mathrm{l}$, potassium $3.3 \mathrm{mmol} / \mathrm{l}$, chloride $82 \mathrm{mmol} / \mathrm{l}$, albumin $24 \mathrm{~g} / \mathrm{l}$. Initial management consisted of intravenous fluids in the form of sodium lactate only, followed by $3.3 \%$ dextrose with $0.3 \%$ saline at a rate of $65 \mathrm{ml}$ per hour.

Ten hours after admission the child had a generalised convulsion of 2 minutes' duration. $\mathrm{He}$ became apnoeic, with a thready pulse and unrecordable blood pressure, and did not respond to ventilation, external cardiac massage, intravenous dextrose, and calcium gluconate. However, after intravenous administration of $200 \mathrm{mg}$ hydrocortisone hemisuccinate, spontaneous respirations returned and the systolic blood pressure rose to $80 \mathrm{mmHg}$. Within 24 hours he was afebrile. The stomatitis and nappy rash cleared without treatment in 72 hours by which time the peripheral white cell count had returned to normal. During this period, hydrocortisone was administered every 6 hours; it was stopped 6 days later.

The pharmacy records showed that this child had received $787 \mathrm{~g}$ of $0.1 \%$ betamethasone-17-valerate cream during a 7-month period. Weight loss during that time was followed by catch-up in weight and rapid linear growth after the steroid was stopped (Figure).

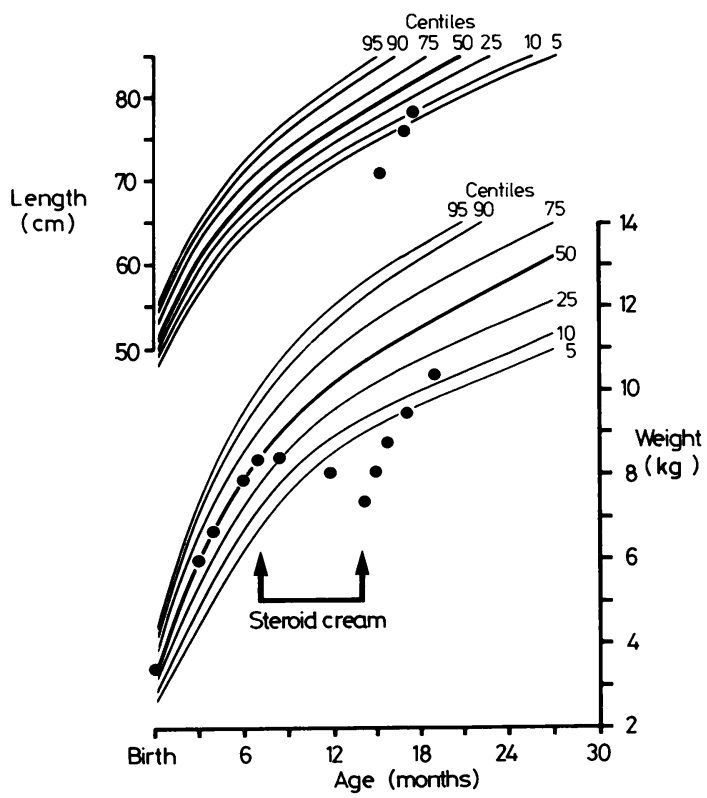

Figure Weight loss during treatment with betamethasone-17-valerate cream, followed by catch-up growth when it was stopped.

Case 3. A $12 \frac{1}{2}$-year-old girl was referred for investigation of obesity. Four months earlier she had started a course of five $25 \mathrm{mg}$ injections of triamcinolone diacetate given into an area of alopecia on the scalp at fortnightly intervals; the last injection had been 2 months before admission. During this treatment her weight increased by $11 \mathrm{lb}$ and facial swelling developed. One month before admission plasma cortisol levels were $4.5 \mu \mathrm{g} / 100 \mathrm{ml}$ $(124 \cdot 2 \mathrm{nmol} / \mathrm{l})$ at 0800 and again at 2000 hours.

On examination her height was $154 \mathrm{~cm}$ (50th centile) and her weight $57.65 \mathrm{~kg}$ (>90th centile). 
Blood pressure was $125 / 80 \mathrm{mmHg}$ and pulse $86 / \mathrm{min}$. There was an area of alopecia on the scalp with many broken hairs and some palpable roots. She was moon faced and had a slight buffalo hump. Purple striae were present on the buttocks and thighs, and behind the knees.

Investigation (Table) showed diminished cortisol response to adrenocorticotrophic hormone (ACTH) stimulation. These values and the previously recorded plasma cortisol levels indicated suppression of the HPA axis which was now in the process of recovery. Observation during her time in hospital revealed that the patient's alopecia resulted from trichotillomania.

Case 4. A 14 - 8-year-old girl was admitted to hospital with a 1-month history of weakness, lethargy, arthralgia, acne, and facial swelling which her parents interpreted as rapid weight gain. Seven weeks previously she had received a single intralesional injection of $240 \mathrm{mg}$ triamcinolone diacetate into a large scar beneath the left axilla and extending on to the back that had resulted from a 3rd degree burn sustained 3 years earlier.

On examination her height and weight were both on the 25th centile. Blood pressure was $110 / 60$ $\mathrm{mmHg}$. She had rounded facies without plethora, a mild buffalo hump, and mild truncal obesity. There was severe papulopustular acne over the face and upper chest wall, and purple striae were present on both thighs.

Investigation (Table) showed suppression of the HPA axis. Three months later normal diurnal variation and response of plasma cortisols to ACTH stimulation had returned.

\section{Discussion}

Topical corticosteroids are often prescribed for children. Their effects are enhanced by factors relating to the site, size, and condition of the treatment area; dosage and length of application; vehicle used; and the employment of occlusion. Age is also important as the child's thin stratum corneum predisposes to the absorption of topical medications ${ }^{13}$ and the ratio of surface area to weight is greater in the child than the adult.

Occlusion of the treatment area increases penetration 100 -fold or more, as determined by vasoconstriction. ${ }^{14}$ This may lead to temporary suppression of pituitary-adrenal function, even with $1 \%$ hydrocortisone cream applied to a large area. ${ }^{15}$ The use of fluorinated corticosteroids with their greater inherent potency further increases the likelihood of undesirable systemic effects.

In Case 1 the widespread distribution and inflammatory nature of the lesions facilitated steroid absorption which led to adrenal suppression. In Case 2, as in the cases of Roussounis ${ }^{9}$ and Johns and Bower, ${ }^{2}$ the important factor was long-term application of fluorinated corticosteroid to a localised area, the moist and self-occlusive perineum. Scrotal application of radiolabelled steroids results in up to $35 \%$ urinary excretion, a much greater percentage than results from application to most other areas. ${ }^{16}$ In addition, the frequent use of a nappy acted as an occlusive dressing in this case. We did not have the opportunity to study adrenal insufficiency before starting hydrocortisone therapy; nevertheless, the acute episode of hypotension after 7 months of excessive betamethasone-17-valerate application may have reflected an adrenal crisis in a patient whose impaired HPA axis had been unmasked by the stress of acute infection. Marked growth retardation with proved suppression of the HPA axis has been reported in children treated with fluorinated corticosteroids. ${ }^{2} 4$

Cases 3 and 4 show that unusual complications can result from this fairly rare mode of treatment in paediatric practice. No doubt other cases have been overlooked or have not been reported because the patients had less florid signs. The danger of adrenal suppression with intralesional corticosteroids is increased if the dose is too large or the drug incorrectly administered. Unfortunately, dosage guidelines for the young patient are available only for the management of keloids. ${ }^{17}$ It is suggested that the risk of systemic absorption is greatly reduced if accidental infiltration into normal tissues adjacent to or beneath the scar does not occur. ${ }^{17}$

With non-keloid conditions, such as alopecia, one cannot avoid injecting deep to the stratum corneum which is the main barrier to absorption. In such conditions much smaller doses of triamcinolone, generally diluted, are recommended for adults. Guidelines for children are not easy to find; consequently we adopt a conservative approach using diluted corticosteroid preparations. In selected cases of alopecia areata, one of us (JT) uses $10 \mathrm{mg} / \mathrm{ml}$ triamcinolone diluted 5:1 with xylocaine to give a concentration of $2 \mathrm{mg} / \mathrm{ml}$ of which about $1 \mathrm{mg}$ is $\sigma$ injected. This is repeated monthly, as dictated by response. In an area of increased vascularity-such as the scalp-where disappearance of the corticosteroid is presumably quicker than from the avascular keloid, such frequency of injection is indicated to ensure a continuous effect.

In skin conditions requiring the use of topical applications the most potent preparations are seldom indicated as first-line therapy. For example, the routine use of fluorinated corticosteroids appears to have little advantage over $1 \%$ hydrocortisone in 
the management of childhood eczema. ${ }^{18}$ The calculation of an effective, safe dose is made difficult because of variability of the local epidermal barrier in disease states and the physician has to titrate dose against response in each patient. A reasonable approach therefore may be to treat the less severe steroid-responsive dermatoses initially with a hydrocortisone preparation. If there is no response to $1 \%$ hydrocortisone, one of the least potent fluorinated steroids may be selected and diluted with an appropriate base before more potent preparations are tried.

Children treated with fluorinated steroids or intralesional corticosteroid injections may develop suppression of the HPA axis. In such cases, coverage with oral or parenteral cortisone is indicated in the event of infection, surgery, or accident, until full recovery of adrenal function is confirmed by plasma cortisols and response to ACTH stimulation. ${ }^{19}$ Meanwhile, an attempt should be made to reduce the strength of the topical preparation to the minimum necessary to maintain an adequate therapeutic response.

\section{References}

1 Fanconi G. Hemmung des Wachstums bei einem Säugling durch die zu intensive Anwendung einer $1 \%$ igen Hydrocortisonsalbe auf der Haut bei generalisiertem Ekzem. Helv Paediatr Acta 1962; 17: 267-8.

2 Johns A M, Bower B D. Wasting of napkin area after repeated use of fluorinated steroid ointment. $\mathrm{Br}$ Med $\mathrm{J}$ 1970 ; i: 347-8.

3 Benson P F, Pharoah P O D. Benign intracranial hypertension due to adrenal steroid therapy. Guy's Hosp Rep $1960 ; 109$ : 212-8.

4 Vermeer B J, Heremans G F P. A case of growth retardation and Cushing's syndrome due to excessive application of betamethasone-17-valerate ointment. Dermatologica 1974; 149: 299-304.

5 Munro D D. Percutaneous absorption in humans with particular reference to topical steroids and their systemic influence. MD thesis, University of London 1975.

6 Feinblatt B I, Aceto T, Jr, Beckhorn G, Bruck E. Percutaneous absorption of hydrocortisone in children. Am J Dis Child 1966; 112: 218-24.
7 Ronayette D, Hennequin D, Bouquier J J, Bonnetblanc J M. Syndrome de Cushing induit par corticothérapie locale chez un nourrisson. Nouv Presse Med 1978; 7: 368.

8 Keipert J A, Kelly R. Temporary Cushing's syndrome from percutaneous absorption of betamethasone-17valerate. Med J Aust 1971; i: 542-4.

9 Roussounis S H. Benign intracranial hypertension after withdrawal of topical steroids in an infant. $\mathrm{Br} \mathrm{Med} J$ 1976 ; ii: 564.

10 Ketchum L D, Cohen I K, Masters F W. Hypertrophic scars and keloids: a collective review. Plast Reconstr Surg $1974 ; 53$ : 140-54.

11 Abdel-Fattah A M A. Unusual complications of triamcinolone injected keloids: tissue necrosis and systemic corticosteroid effects. Br J Plast Surg 1976; 29: 283.

12 Langston J R, Kolodny S C. Cushing's syndrome associated with the intradermal injection of triamcinolone diacetate. J Oral Surg 1976; 34: 846-9.

13 Munro D D. The effect of percutaneously absorbed steroids on hypothalamic-pituitary-adrenal function after intensive use in in-patients. $B r J$ Dermatol 1976; 94: Supplement 12, 67-76.

14 McKenzie A W, Stoughton R B. Method for comparing percutaneous absorption of steroids. Arch Dermatol $1962 ; 86$ : 608-10.

15 Scoggins R B, Kliman B. Percutaneous absorption of corticosteroids: systemic effects. $N$ Engl J Med 1965; 273: 831-40.

16 Feldmann R J, Maibach H I. Regional variation in percutaneous penetration of ${ }^{14} \mathrm{C}$ cortisol in man. $J$ Invest Dermatol 1967; 48: 181-3.

17 Ketchum L D, Robinson D W, Masters F W. Follow-up on treatment of hypertrophic scars and keloids with triamcinolone. Plast Reconstr Surg 1971 ; 48: 256-9.

18 Feiwel M, James V H T, Barnett E S. Effect of potent topical steroids on plasma-cortisol levels of infants and children with eczema. Lancet $1969 ; \mathrm{i}: 485-7$.

19 Alsever R N, Gotlin R W. Handbook of endocrine tests in adults and children, second edition. Chicago: Year Book Medical Publishers, 1978: 128.

Correspondence to Dr J A Curtis, Department of Paediatrics, Regional Hospital, Wilton, Cork, Ireland.

Received 26 March 1981 